\title{
Surgical treatment for bronhial carcinoid tumors prognostic factors for long-term outcome
}

\author{
D Petrov ${ }^{1 *}$, D Marinova ${ }^{2}$, E Goranov $^{1}$, Y Slavova $^{2}$, G Yankov $^{1}$ \\ From 23rd World Congress of the World Society of Cardio-Thoracic Surgeons \\ Split, Croatia. 12-15 September 2013
}

\section{Background}

The aim of study was to study the prognostic factors after surgery with curative intend for pulmonary carcinoid tumors - typical carcinoid (TCs) and atypical carcinoid (AtCs).

\section{Methods}

Surgically resected specimen (men $\mathrm{n}=59$; women $\mathrm{n}=72$, age $48 \pm 15)$ from $111 \mathrm{TC}(84.7 \%)$ and 20 AtC (15.3\%) patients were studied. The histological type, T-status, $\mathrm{N}$-status (TC - 94 N0, $17 \mathrm{~N} 1 / 2$; AtC - $16 \mathrm{N0}, 4 \mathrm{~N} 1$ ), pTNM stage (TC-I $\mathrm{n}=81$, II $\mathrm{n}=17$, III+IV $=13$; AtC-I $\mathrm{n}=12$, II-IV $\mathrm{n}=8$ ), surgery (55 simple lobectomies, 16 bilobectomies, 24 pneumonectomies (4 extended), 15 segmentectomies, 16 sleeve lobectomy (in 2 of them combined with sleeve resection of pulmonary artery), 5 sleeve resection of main bronchus), and immunohistochemical expression (on $64 \mathrm{TCs}$ and 13 AtCs) of p-HspB5, Hsp27 and mTOR were evaluated. Kaplan-Meier, Wilcoxon, Cox regression analyses were the statistical methods used.

\section{Results}

The overall 5-, 10- and 15-year survival for TCs were $84 \%, 70 \%$ and $62 \%$ respectively; and for AtCs-53\% and $0 \%$. The difference in mean survival time between TCs (14 years) and AtCs $(7$ years) was significant $(\mathrm{p}=0.004)$. The median survival time was significantly longer in N0 status (N0-213 months, N1/2-54, p = 0.002), in I and II pTNM status (I/II-213 months, III/IV-27, p $=0.020)$ and in cases positive for mTOR $(\mathrm{p}=0.035)$. T status, $\mathrm{p}-\mathrm{HspB}$, Hsp27 expression were not statistically significant factors for survival $(\mathrm{p}>0.05)$. The Cox analysis

\footnotetext{
*Correspondence: danail_petrov@hotmail.com

'Thoracic Surgery, Saint Sophia University Hospital for Pulmonary Diseases, Medical University, Sofia, Bulgaria

Full list of author information is available at the end of the article
}

confirmed the prognostic significance of histology type (HR 3.32; $\mathrm{p}=0.007), \mathrm{N}$ status (HR 3.51; $\mathrm{p}=0.014)$ and pTNM stage (HR 11.27; $\mathrm{p}<0.001$ ).

\section{Conclusion}

Postoperative survival is significantly related to the histology type, $\mathrm{N}$ status, pTNM stage and mTOR expression.

Authors' details

${ }^{1}$ Thoracic Surgery, Saint Sophia University Hospital for Pulmonary Diseases, Medical University, Sofia, Bulgaria. ${ }^{2}$ Pneumology, Saint Sophia University Hospital for Pulmonary Diseases, Medical University, Sofia, Bulgaria.

Published: 11 September 2013

\section{doi:10.1186/1749-8090-8-S1-O231}

Cite this article as: Petrov et al.: Surgical treatment for bronhial carcinoid tumors prognostic factors for long-term outcome. Journal of Cardiothoracic Surgery 2013 8(Suppl 1):O231.

\section{Submit your next manuscript to BioMed Central and take full advantage of: \\ - Convenient online submission \\ - Thorough peer review \\ - No space constraints or color figure charges \\ - Immediate publication on acceptance \\ - Inclusion in PubMed, CAS, Scopus and Google Scholar \\ - Research which is freely available for redistribution

